\title{
Examining Digital Literacy Competences and Learning Habits of Open and Distance Learners
}

\author{
Nilgun Ozdamar-Keskin, Fatma Zeynep Ozata, \& Kerim Banar \\ Anadolu University, Turkey \\ Karl Royle \\ University of Wolverhampton, United Kingdom
}

\begin{abstract}
The purpose of the study is to examine digital literacy competences and learning habits of learners enrolled in the open and distance education system of Anadolu University in Turkey. Data were gathered from 20.172 open and distance learners through a survey which included four parts: demographic information, abilities to use digital technologies, learning habits, preferences in using digital technologies for learning purposes. Principal Component Factor Analysis was applied in order to group and classify the attitudes and statements of the learners in their personal learning preferences, problem solving skills, project work skills, and abilities to use digital tools for learning purposes. Their personal learning preferences produced five factors: visual, auditory, dependent, collaborative, and readingwriting learning styles. According to the results of the study, learners believe that they have problem solving and project working skills to deal with educational difficulties. However, they seem to have only basic competences of digital literacy and the skills to use information and communication technologies at a basic level. They need training on how to use digital tools more efficiently for learning purposes. Further research is needed to explore how to increase the use of digital tools for the purpose of effective learning and also how to design learning environments to improve digital literacy of open and distance learners.
\end{abstract}

Keywords: Open and distance learning; Digital literacy; Learning preferences; Learning styles; Problem solving; Project skills

\section{Introduction}

Mega-universities are distance teaching institutions with over 100.000 active students in degree-level courses (Daniel, 1996) and intend to meet the adults' and lifelong learners' educational needs. Some mega-universities especially in developing countries such as India, Iran and Turkey have the largest enrollment of active students (over 1 million) across all campuses (including off-campus). Anadolu University, as one of the mega universities, has laid the foundations of distance learning in Turkey and it consolidates its position with open learning and teaching activities carried out over the last 30 years and today. It serves over 1.5 million open and distance learners with open teaching institutions including three faculties: Faculty of Open Education, Faculty of Business, and Faculty of Economics. Anadolu University provides a variety of delivery options such as visual classrooms, e-learning portals, e-portfolio systems, and interactive books where individual and cooperative work is supported and learners are 
encouraged to use technology in their learning. These groups of learners are quite diverse in terms of age, digital literacy competencies, and learning habits.

This study is a part of "A Multiplatform M-Learning System for More Qualified Courses in ICT Era" project sponsored by the British Council and Anadolu University. The focus for the project is the development, deployment, and evaluation of a mobile application to support undergraduate/graduate programs (Ozdamar-Keskin et al., 2012). Anadolu University, Okan University, and the University of Wolverhampton have worked together on surveying the digital 'habits', which is access, expectations, and experiences of mobile digital technologies of their staff and student populations. This study examines the abilities of Anadolu University's open and distance learners to use digital technologies in digital life and to use these technologies for the purpose of effective learning; it also identifies the general profile of learners by analyzing their digital literacy and learning habits for designing mobile qualified courses. The findings gathered in the study may be used to assess the learner needs regarding digital literacy. Thus, administrators, education developers, researchers working on innovative or creative learning projects may benefit from understanding the learner profiles in these areas by making a greater match or fit between learners and the programs.

\section{Digital Life, Digital Literacy, and Learning Habits}

With the opportunities provided by information and communication technologies, the most important value of the 21st century is $24 / 7$ access to information in the fastest way within the frame of one needs. With the advent of mobility, digital tools have become an inseparable part of people's lives and also enhanced three meaningful factors such as speed, virtuality, and networking (Rivoltella, 2008). According to a recent report published by the International Telecommunications Union (2013), there are 7 billion mobile customers throughout the world; $27 \%$ of these users benefit from 3G/4G mobile services. The latest numbers which were announced in 2013 by Apple show that 50 billion applications have been downloaded in the last 5 years. Many people access to information they need via web sites such as Google, YouTube, and Wikipedia. E-mail is the most popular tool among people preferred for sending and receiving messages quickly. Online banking and shopping is spreading among people from day to day, social networks like Facebook and Twitter are encouraging people to cooperate by setting the content of communication and sharing it. As it is usually observed, no matter how old people are, using digital technologies in the digital era have become a vital need (Goodfellow, 2011).

Individuals using digital tools in the information age have turned into participative and active individuals who gather, process, and produce information (Sharkey \& Brandt, 2008). A digital literate person uses technology effectively in order to do research, reach information sources, read-write and comment efficiently, make reasonable choices, and make right decisions. Digital literacy encourages curiosity and creativity and also enables the individual to evaluate the information that has been gathered in a critical way. By increasing the ability to use digital resources, digital literacy helps individuals feel themselves relatively secure at technology usage (McLoughlin, 2011). However, today still many people are in need of training so that they can use and manage the multiple and loose information network with the help of technology (FutureLab, 2010).

Digital literacy is described as creating social mores within individuals' private lives and the ability to reflect on this process using digital tools appropriately. Further, digital literacy involves identifying digital resources and content, reaching, managing, combining, evaluating, and 
making analysis/synthesis, forming new data, creating new ways of media expressions and making it possible to communicate with others (Martin, 2008). Digital literacy requires multiple literacy skills (Shariman, Razak, \& Noor, 2012). As seen in Table 1, in the field of educational technology the sub-discipline areas of digital literacy are; computer literacy, technology literacy, information literacy, media literacy, visual literacy, and communication literacy (Covello, 2010; Goodfellow, 2011; Simsek \& Simsek, 2013).

Digital technologies which people use and are influenced by are multiple, rich, and complex. Digital literacy is related to learners' abilities to find and choose reliable as well as relevant information within complex networks (Gilster, 1997). A digitally literate person knows the most effective and efficient ways to reach the information he/she needs. That is why, he/she has a good grasp of ways of searching information. Digital literacy is knowing how to select and use the digital technologies where, when, and in a purposeful way. Digital literacy is also related to critical thinking about the opportunities and benefits of digital technologies used frequently such as Web 2.0, social networks, and mobile applications (McLoughlin, 2011).

Table 1. Subdisciplines of Digital Literacy

\begin{tabular}{ll}
\hline Sub-Discipline & Definition \\
\hline Information Literacy & $\begin{array}{l}\text { Finding and locating sources, analyzing and synthesizing the material, } \\
\text { evaluating the credibility of the source, using and citing ethically and legally, } \\
\text { focusing topics and formulating research questions in an accurate, effective, } \\
\text { and efficient manner. }\end{array}$ \\
Computer Literacy & $\begin{array}{l}\text { An understanding of how to use computers and application software for } \\
\text { practical purposes. }\end{array}$ \\
Media Literacy & $\begin{array}{l}\text { A series of communication competencies, including the ability to access, } \\
\text { analyze, evaluate and communicate information in a variety of forms including } \\
\text { print and non-print messages. }\end{array}$ \\
Lommunication & $\begin{array}{l}\text { Learners must be able to communicate effectively as individuals and work } \\
\text { collaboratively in groups, using publishing technologies (word processor, } \\
\text { database, spreadsheet, drawing tools...), the Internet, as well as other } \\
\text { electronic and telecommunication tools. }\end{array}$ \\
Visual Literacy & $\begin{array}{l}\text { The ability to 'read,' interpret, and understand information presented in } \\
\text { pictorial or graphic images; the ability to turn information of all types into } \\
\text { pictures, graphics, or forms that help communicate the information; a group } \\
\text { of competencies that allows humans to discriminate and interpret the visible } \\
\text { action, objects, and/or symbols, natural or constructed, that they encounter in } \\
\text { the environment. } \\
\text { Computer skills and the ability to use computers and other technology to } \\
\text { improve learning, productivity, and performance. }\end{array}$ \\
\hline
\end{tabular}

From another perspective, digital literacy is the social process of creating the meaning (Future Lab, 2010). It enables the learners to become active participants in their educational, social, cultural, and intellectual life. As digital technologies provide opportunities for team work, it develops the skills to work with different types of people. For example, Wiki web sites encourage cooperation by allowing the learners to write a text, edit and update it. Google Docs, an online web based application, enables text based documents to be uploaded whereas it also maintains 
a ground for sharing documents among computers connected to Internet and allows people to edit texts by teamwork.

\section{Learning Style}

Learning style is considered as an important feature for learner preferences. The term of "learning style" refers to the view that different people learn information in different ways (Ozata \& Ozdamar-Keskin, 2014). It is related to one's characteristic ways of perceiving, processing, and interpreting information (Simsek, 2004). There are a number of different learning style models in the literature. We have chosen Fleming and Mills's VARK Model and Grasha and Reichmann's Learning Style Model to clarify our research objectives.

Fleming and Mills's VARK (Visual, Auditory, Reading, Kinesthetic) Model (1992) refers to four learning style dimensions (http://www.vark-learn.com/english/page.asp?p=categories). Visual learning style (the depiction of information in maps, diagrams, charts etc.), Auditory learning style (the preference for information that is "heard or spoken."), Reading-writing learning style (the preference for information displayed as words), Kinesthetic learning style (the preference related to the use of experience and practice (simulated or real). On the other hand, Grasha and Reichmann's Learning Style Model (1996) classifies learning styles by three dimensions and six learning styles (http://academic.cuesta.edu/wholehealth/disted/about_styles.htm). Avoidant or participant learning styles (Avoidant students are not enthusiastic about learning content and attending class while participant students enjoy going to class and take part in as much of the course activities.) Competitive or collaborative learning styles (Competitive students who learn material in order to perform better than others in the class while collaborative students enjoy working with their peers and learning by sharing ideas and talents.) Dependent or independent learning styles (Dependent students show little intellectual curiosity and who learn only what is required while independent students who like to think for themselves and are confident in their learning abilities).

\section{The Purpose of the Study}

The purpose of this study is to examine the digital literacy competences and learning habits of open and distance learners at Anadolu University. Within this context, the research questions are listed as follows:

1. What are the abilities of the learners to use the digital technologies in digital life?

a. Which digital technologies do the learners have access to?

b. How often do the learners use digital technologies?

c. What are the purposes of the learners in using digital technologies?

2. What are the learning habits of the learners?

a. What are the personal learning preferences of the learners?

b. What do learners think/believe about their own problem solving skills?

c. What do learners think/believe about their own project working skills?

3. What are the abilities of the learners in using digital tools for learning purposes? 


\section{Research Design}

Survey methodology was used in this study. The survey consists of four parts: demographic information, abilities to use digital technologies, learning habits, preferences in using digital technologies for learning purposes. The survey was developed by Wolverhampton University Center for Development and Applied Research in Education. After being translated into Turkish, it was submitted to experts' opinion and took its final shape after a pilot study. The survey was issued electronically, was distributed via SMS and e-mail to the open and distance learners in 2012. The data were gathered from 20.172 open and distance learners enrolled in the open and distance education system of Anadolu University including three faculties as Open Education Faculty, Faculty of Business, and Faculty of Economics. The number of the participants in the present study has exceeded the required minimum number (16.406) of respondents needed at the margin error of 10 percentage points when the population has more than 1.500 .000 respondents.

Descriptive data analysis was used for demographic information. The Principal Component Factor Analysis was applied in order to group and classify the attitudes and statements of the learners in their personal learning preferences, problem solving skills, project work skills and abilities to use digital tools for learning purposes. The overall Cronbach's Alpha reliability coefficient for the entire scale was calculated to be 0.74 . We used Cronbach's alpha to estimate the scale of consistency among items in the group. The Cronbach's alpha is generally accepted upon the level of 0.70, albeit it is acceptable at 0.60 in exploratory research (Hair et al., 1998).

\section{Background of Participants}

When we analyze the demographic data of the learners (20.172) who participated in the study, the percentage of male $(56 \%)$ is not far from the percentage of female $(44 \%)$ and participants were mainly in 21-25 (8.266 learners) and 26-35 (6.854 learners) age groups. The majority of the participants were in their 1st, 2nd and 3rd year of the open and distance learning period. When the demographic data of the learners were examined by faculty, the majority were in the Open Education Faculty. Table 2 gives the demographic details of the participants.

Table 2. Demographic Details of the Participants $(\mathrm{N}=20.172)$

\begin{tabular}{lclc}
\hline Properties & $\%$ & Properties & $\%$ \\
\hline $\begin{array}{l}\text { Gender } \\
\text { Male }\end{array}$ & 56 & $\begin{array}{l}\text { Faculty } \\
\text { Faculty of Economics }\end{array}$ & 20 \\
Female & 44 & $\begin{array}{l}\text { Faculty of Business } \\
\text { Administration }\end{array}$ & 35 \\
Age & & Faculty of Open Education & 45 \\
$18-20$ & 8 & Year & \\
$21-25$ & 41 & First year & 27 \\
$26-35$ & 34 & Second year & 25 \\
$36-45$ & 13 & Third year & 24 \\
$46-55$ & 3 & Fourth year & 15 \\
56 and above & 1 & More than 4 years & 9 \\
\hline
\end{tabular}

\section{The Survey Design}


The survey used for the digital habits of learners was derived from previous work by Royle and Hadfield (2012), Hadfield et al. (2009), Claxton et al. (2004), Kay et al. (2009), Kerrigan (2012). These sources all underpinned the various sections of the survey in an attempt to map the digital life and habits of learners.

Apart from the biographical Section 2, Section 3 through Section 5 dealt with the issues relating to the specific sets of values and attributes pertaining to the sources above. These were supplemented by some questions related to current technologies which had been implemented since the first questionnaires that were used and designed in previous projects. Section 3 concentrated on learners' learning orientation, referencing the work of Hunt, Eagle, and Kitchen, 2004 and the work of Claxton et al. (2004) on notions of learning power which includes the following classifications:

- Resilience: Being ready, willing and able to work through difficulties.

- Resourcefulness: Being ready, willing and able to learn in different ways.

- Reflectiveness: Being ready, willing and able to become more strategic about learning.

- Reciprocity: Being ready, willing and able to learn alone or with other people, using communication skills and empathy

The purpose of this section was to note the extent to which students preferred working in a way that was compatible with remote and distance learning and how much support they would need. In particular, it was expected to provide information on how much knowledge learners have about the way they like to learn and their knowledge about being an effective learner. This gives insight into the gaps in students' knowledge about learning and how they might become better and more independent learners. It may point to a need for learning designers to focus on the processes of learning such as reflection on performance and self-evaluation of a range of learning dispositions. In previous studies, it was noted that students would have a tendency to over report their abilities in certain areas so it was important to consider any negative responses in the survey carefully.

Section 4 of the survey was predominantly based on the classification of Next Generation User Skills (NGUS) as described by Kay et al. (2009). NGUS looked at the needs of industry, learners' existing digital literacies and the products from existing curricula including 34 sets of ICT competencies to develop a framework around 5 groups. Two competency groups that represent the underpinning foundations of personal confidence are assumed to be required by all users:

- Digital Literacy - including safe and social conduct

- Digital Independence - including management of the IT environment

These support three broad and complementary areas of competence:

- Inquiry - including the ability to investigate resources

- Participation - including the ability to collaborate

- Production - including ability to create media"

Thus, Section 4 of the survey used these competencies so that a picture of learners' capabilities would emerge that may be vital for designing learning for different cohorts/age groups and dispositions. Therefore, this section would tell us which skills learners possess in terms of their use of technology. This allows designers and educators to realize the extent to which learners actually possess the skills with technology and enables them to consider how those skills can be acquired or improved. This may also show educators' practices, knowledge, and skills so that 
students can learn effectively. It is also useful to recognize the skills that students possess so that these can be used to mentor and coach others.

The final section of the survey combines learners' non educational use of technology with the key question of "how they use the technology they have". This section was derived from previous questionnaires and from the work of Kerrigan (2012) and the Digital Literacies in Transition Project. This section focuses on the use of technologies for a variety of purposes including studying and learning. In particular, this section provides insights into what learners are engaging with digitally at home and when not studying. This should also give insights into which platforms can be used to reach users although there are ethical issues about invading learners' space that need further investigating. However, great inroads have been made in this area, particularly in the use of Facebook for learning but this should be tempered by a responsibility to engage learners thinking in regard to an NGUS area, such as maintaining and protecting their digital identity online and safety. For educators and designers, an awareness of their learners' digital habits should allow them to construct learning events that transfer those habits into institution derived formal digital learning.

\section{Findings and Discussion}

\section{Learners' Abilities to Use Digital Technologies}

In this section, findings regarding open and distance learners' ownership of information and communication technologies and their frequencies of usage as well as their purposes of using technology are presented.

\section{Ownership of Information and Communication Technologies}

The majority of the respondents have personal computers at their houses (92\%). However, it appears that $36 \%$ of the computers are used only by the learners and $46 \%$ of the computers are located in the learners' own room. In other words, it has been observed that most of the learners who have personal computers share their computers with other family members. When it comes to the Internet connection used in the houses, $54 \%$ preferred wireless network and it was observed that $12 \%$ owned a personal computer without Internet connection at their house.

When other digital tools are in question, mobile phones with internet access (55\%), laptops $(48 \%)$ and desktops (46\%) are the most common ones that the learners possess. These tools are followed by digital cameras (44\%), smart phones (28\%) and iPod or MP3 players (24\%). The percentage of the respondents having a mobile phone with internet access $(55 \%)$ is higher than the percentage of the respondents having a smart phone $(\% 28)$ and the percentage of the respondents having a mobile phone without Internet access (20\%). Further, it is seen that the percentage of holding a game console $(10 \%)$, netbook $(9 \%)$, tablets $(6 \%)$ and e-book reader, kindle or nook is comparatively low. The ownership of proper technology is an important issue and this situation may create serious challenges in term of improving learners' digital literacy skills.

\section{The Frequency of Using Technology and the Purposes}


Most of the respondents stated that they spend around 2-3 hours in a day online. Among the participants $17 \%$ spend between $4-6$ hours online and $15 \%$ spend more than 6 hours a day. Figure 1 presents the use of digital tools and respondents' purposes in using digital tools.

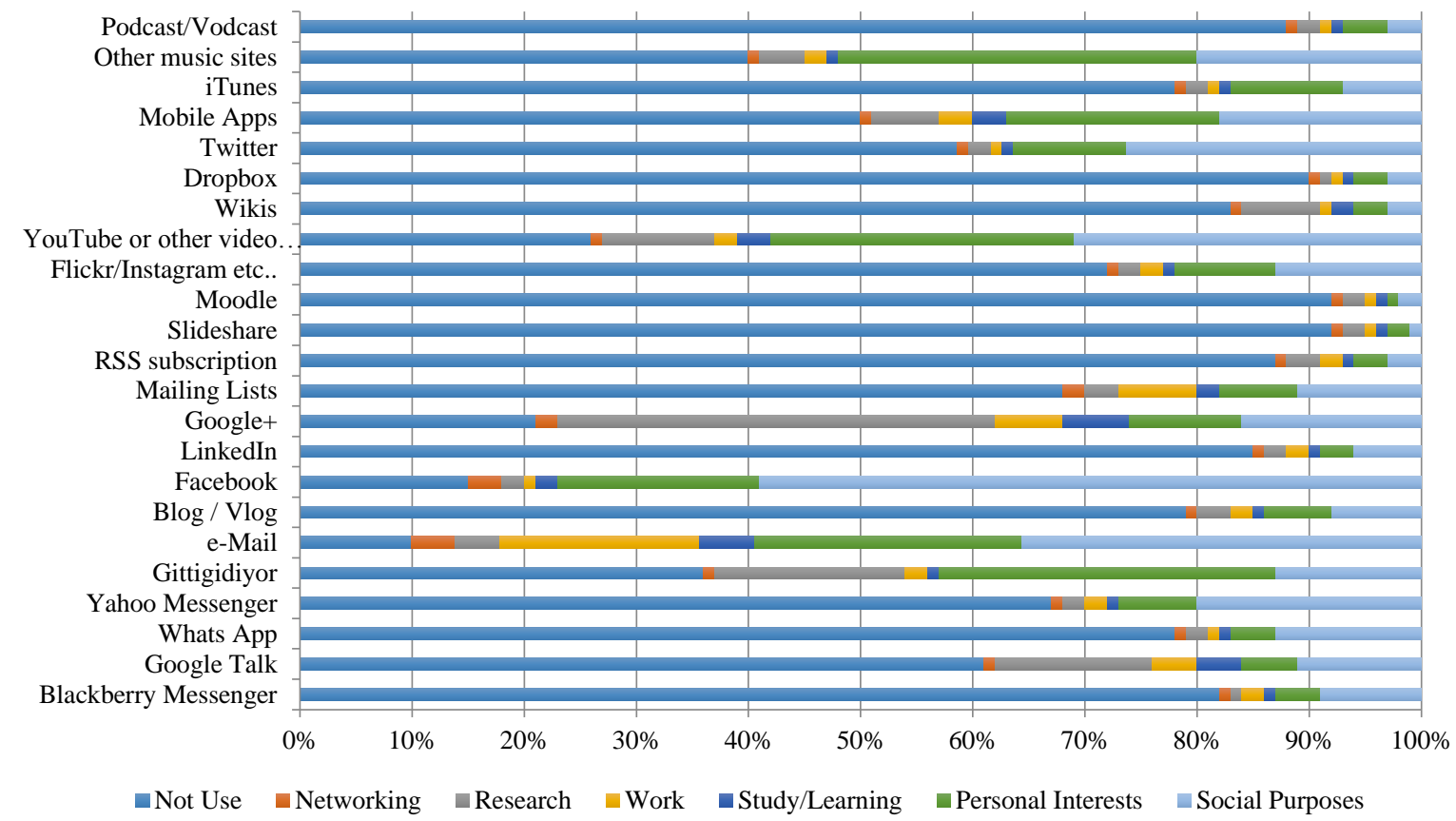

Figure 1. Participants' Habits of Using Digital Tools

Respondents' purposes in using current web sites and digital tools were also evaluated. However, the web sites and digital tools in question are not commonly used by them. It was seen that digital tools are mainly used for social purposes or within the frame of personal interests. Music web sites, mobile applications, Twitter, YouTube, e-mail and Gittigidiyor (a popular shopping website in Turkey such as eBay) are the top tools of the learners used for these purposes. It is observed that these tools are used rarely for the purpose of education. The learners with the study/learning purpose preferred, by order, e-mail, mobile applications, YouTube and other video sharing web sites.

\section{Learning Habits}

In this section, open and distance learners' personal learning preferences, problem solving skills, and project working skills are analyzed.

\section{Personal Learning Preferences}

Five factors were obtained as a result of the factor analysis carried out for the purpose of identifying the personal learning preferences of the learners (Table 3). The alpha values of the first three factors are $0.716,0.714$ and 0.732 respectively, representing high internal consistency of these components. However, the alpha values of the fourth $(\alpha=0.512)$ and the fifth $(\alpha=$ 0.347 ) factors are quite low, due to the very limited number of items. These five factors explain $57 \%$ of the total variance. 
The first factor represents the learners' "visual learning style" and it has 4 sub items. This factor points out the attitude where students remember the graphics and visuals more than something they listen or read and they prefer to get help from the graphics and visuals while learning new things. The percentage of the variance which is explained in the factor analysis displays the relative importance of the factors (Altunisik et al., 2012). According to this first factor "visual learning style" explains the biggest part of the variance with a ratio of $23 \%$. This preference includes the depiction of information in maps, diagrams, charts, graphs, flowcharts, labeled diagrams, and all the symbolic arrows, circles, hierarchies and other devices that people use to represent what could have been presented in words. (Fleming \& Mills, 1992; Hunt, Eagle, \& Kitchen, 2004). Using game/simulation, picture and graphics during the learning process are the important elements observed in this factor.

The second factor represents students "auditory learning style" and it has 4 sub items. This factor refers to the attitude where students prefer listening to the things that are being told instead of reading. "Auditory learning style" explains $11 \%$ of the total variance. This perceptual mode describes a preference for information that is "heard or spoken" (Fleming \& Mills, 1992). The item with the highest ratio within this factor is to prefer listening to an instructor instead of reading the course materials.

The third factor represents the "dependent learning style" and it has 2 sub items. Dependent learning refers to an expert guided course preference. Students who prefer dependent learning think that education is finding the "right answer" and this information is perceived to be held by the lecturer (Grasha \& Reichmann, 1996; Hunt, Eagle, \& Kitchen, 2004). The factor in the study covers the students' preference to work with an expert and face to face and explains $8 \%$ of the total variance. The mean of these items shows that learners are concerned about studying with an expert face to face.

The fourth factor represents learners' "collaborative learning style" that is a preference of working collaboratively rather than working alone and it has 4 sub items. It covers the facts like learning within a group or doing collective work (Grasha \& Reichmann, 1996). This factor explains $8 \%$ of the total variance. The item with the lowest ratio within this factor is desire to do a collective work online.

The fifth and the last factor represents the "reading and writing learning style" and it has 2 sub items. Within this factor, the attitudes of the learners showing their preference on reading the written materials related with the course rather than listening are stated. This factor explains $6 \%$ of the total variance. However, the answers students have given demonstrate that choice of learning by written material is not very high.

Table 3. Factor Analysis Results for Personal Learning Preferences ( $N=20.172$ )

\begin{tabular}{llll}
\hline Items & M & SD & Factors \\
\end{tabular}




$\begin{array}{lllll}1 & 2 & 3 & 4 & 5\end{array}$

\section{1st Factor: Visual Learning Style}

I prefer to obtain new information by

figures or graphics rather than written or oral means.

I remember better the things that I see on pictures or on graphics more than the things I listen or read.

I like to use game and simulation in learning.

I draw simple graphics, figures or charts to summarize the course subjects.

2nd Factor: Auditory Learning Style

I prefer listening to reading.

I understand better if someone tells me the subject instead of reading.

I remember better the things I heard rather than the things I saw.

I prefer listening to the instructor rather than reading the documents.

3rd Factor: Dependent Learning Style I prefer to study face to face.

I prefer to study with an expert.

4th Factor: Collaborative Learning Style I prefer to study within a group or with a friend.

I prefer to study individually/ independently.

I learn by watching other people.

I prefer to do a collective study online.

\section{5th Factor: Reading-Writing Learner}

Style

I find more useful a written summary of a class compared to a one done by

figures or orally.

I remember better the things that are written rather than the told ones.

\section{Corevalue}

Declared Variance (\%)

Cronbach Alfa

$\begin{array}{lll}2,83 & , 81 & , 775 \\ 2,89 & , 7966 \\ 2,64 & , 60 & , 651 \\ 2,79 & , 77 & , 651\end{array}$

2,70 ,83

,755

,707

, 669

,632

$\begin{array}{lll}3,13 & , 74 & , 815 \\ 3,28 & , 72 & , 797\end{array}$

$2,79 \quad 83$

, 738

$2,74,83$

,720

, 538

, 452

Note: 1=Definitely not agree, 4= Definitely agree.

When all these factors are evaluated together by observing the mentioned variance ratios, it can be stated that students prefer learning by graphics/visuals and by listening compared to the other methods. The percentage ratio of the variance (57\%) explained by these five factors can be mentioned as high. Comparably, the study of Ozata and Ozdamar- Keskin (2014), which examined learning orientations of 168 business school students at Anadolu University, has produced the same five factors as visual, auditory, dependent, collaborative, and readingwriting skills. 


\section{Problem Solving Skills}

Three factors have been obtained as a result of the factor analysis which is conducted to understand the beliefs of the students related with problem solving skills (Table 4). These 3 factors explain $65 \%$ of the total variance. The alpha values of the first two factors are acceptable $(0.781$ and 0.670$)$ and represent high internal consistency of these components. However, the alpha value for the third factor cannot be calculated due to the inadequate number of items (only 1 item).

The first factor is named as "working on a problem". The 4 sub items of this factor cover statements about identifying the problem and solving it. "Working on a problem" as being the first factor explains the biggest part of the total variance which is $41 \%$. "Asking the right questions to solve the problem" and "gathering the necessary data" are the items that have the highest means within this factor.

Second factor is named as "evaluating the solution methods". The 3 sub items within this factor cover student attitudes towards evaluating the alternative solution methods, solving the problem without giving up, and evaluating their progress. "Evaluating the solution methods" being the second factor explains $12 \%$ of the total variance. Within this factor, item "not giving up easily" got the highest mean.

The third and the last factor is named as "avoid solving a problem". Only one item takes place within this factor and it points out students' trust in their friends about problem solving. This factor explains $11 \%$ of the total variance. However, the answers that the students have given show that the ratio of third factor is not very high.

When all these factors are evaluated together by observing the variance percentages which are indicated, the factor "working on a problem" is a primary issue when compared to other factors. The percentage the variance explained by these three factors $(65 \%)$ can be considered as high.

Table 4. Factor Analysis Results for Problem Solving Skills ( $N=20.172)$

\begin{tabular}{|c|c|c|c|c|c|}
\hline \multirow{2}{*}{ Items } & \multirow{2}{*}{ M } & \multirow{2}{*}{ SD } & \multicolumn{3}{|c|}{ Factors } \\
\hline & & & 1 & 2 & 3 \\
\hline \multicolumn{6}{|l|}{ 1st Factor: Working on a problem } \\
\hline $\begin{array}{l}\text { I am good at identifying the problems that } \\
\text { arise. }\end{array}$ & 2,94 & ,66 & 775 & & \\
\hline $\begin{array}{l}\text { I can use the necessary information in order to } \\
\text { solve a problem. }\end{array}$ & 3,05 & ,66 & 761 & & \\
\hline $\begin{array}{l}\text { I can use a systematic method in order to solve } \\
\text { a problem. }\end{array}$ & 2,77 & ,75 & ,728 & & \\
\hline $\begin{array}{l}\text { I can ask the right questions in order to solve, } \\
\text { learn and understand a problem. }\end{array}$ & 3,00 & 67 & 718 & & \\
\hline \multicolumn{6}{|l|}{ 2nd Factor: Evaluating the solution methods } \\
\hline $\begin{array}{l}\text { I constantly evaluate my progress to be sure } \\
\text { about the method that I am following. }\end{array}$ & 3,08 & ,76 & & ,803 & \\
\hline $\begin{array}{l}\text { I generally think of more than one solution } \\
\text { method in order to do something. }\end{array}$ & 3,12 & ,70 & & ,731 & \\
\hline
\end{tabular}


I do not give up easily while working on a hard task.

3rd Factor: To avoid solving a problem

I generally trust my friends in solving problems.

Corevalue

Declared Variance (\%)

Cronbach Alfa

Note: 1=Definitely not agree, 4= Definitely agree

\section{Project Work Skills}

Three factors were obtained as a result of the factor analysis carried out for the purpose of identifying the project work skills of the students (Table 5). All the alpha values $(0.849,0.773$ and 0.736 ) of these factors are above the level of 0.70 . These three factors together explain $71 \%$ of the total variance.

The first factor is named as "planning". The 3 sub items of this factor cover the statements about planning things which have to be completed before starting a project. "Planning" being the first factor explains $50 \%$ in total variance. Setting a target and time management are the items that have the highest ratio within this factor.

The second factor is named as "project management". The 3 items within this factor cover the statements of the students about people expressing themselves within the frame of project management and reaching the information that is required. "Project management" as a second factor, explains $11 \%$ of the total variance. Within this factor, "maintaining a ground for sharing the ideas freely" is the item with the highest ratio. However, other items within this factor have ratios close to one another.

The third factor is named as "evaluating the results". The 3 items within this factor identify the evaluation process after a work has been completed and getting the feedback. This factor explains $9 \%$ of the total variance. Item having the highest ratio within this factor is about students' thinking over to evaluate themselves after a work is completed.

When all these factors are evaluated together by observing the variance percentages that are indicated, the factor "planning and setting a target" appears to be the main issue when compared to other factors. The percentage of the variance explained by these three factors (71\%) can be stated as pretty high.

Table 5. Factor Analysis Results for Project Work Skills ( $N=20.172)$

\begin{tabular}{|c|c|c|c|c|c|}
\hline \multirow{2}{*}{ Items } & \multirow{2}{*}{$\mathbf{M}$} & \multirow{2}{*}{ SD } & \multicolumn{3}{|c|}{ Factors } \\
\hline & & & 1 & 2 & 3 \\
\hline
\end{tabular}




\section{1st Factor: Planning}

Before I start studying I first think about what to do and make a plan.

I set a target for my tasks and make a time table.

I overview the every phase of my work.

$\begin{array}{lll}3,26 & , 64 & , 863 \\ 3,39 & , 61 & , 807 \\ 3,23 & \text {,62 } & , 787\end{array}$

\section{2nd Factor: Project Management}

In a group study I ensure that everyone has the necessary information they need.

3,18 $\quad$, 62

I do what is necessary and make sure that people can express their ideas freely.

3,29 $\quad$,61 $\quad$,61

In a group study I make sure that each person is suitable for the work he/she is doing.

3,20 , 62

\section{3rd Factor: Evaluation of the Results}

I like to get feedback about the work I had done. Once a task is over, I think over the things I have done good and the things I need to improve. In order to reach a target I can prioritize the works that have to be done according to their importance.

$\begin{array}{ll}3,38 & , 67 \\ 3,46 & , 60\end{array}$

\section{Corevalue}

Declared Variance (\%)

$\begin{array}{rrr}4,547 & 1,051 & , 823 \\ 50,525 & 11,677 & 9,143 \\ , 849 & , 773 & , 736\end{array}$

Cronbach Alfa

Note: In the scale that has been used 1=Definitely do not agree, 4= Definitely agree

\section{Ability to Use Digital Tools For The Purpose of Learning}

Four factors have been obtained as a result of the factor analysis that was conducted to understand the learners' abilities to use digital tools toward learning (Table 6). All the alpha values $(0.897,0.924,0.897$ and 0.860$)$ of these factors are above the critical level of 0,70 and represent a very high internal consistency.

Table 6. Factor Analysis Results for Ability to Use Digital Tools for the Purpose of Learning $(\mathrm{N}=20.172)$

\begin{tabular}{llllllll}
\hline \multirow{2}{*}{ Items } & \multirow{2}{*}{ S } & & \multicolumn{4}{c}{ Factors } \\
\cline { 3 - 7 } & & & & & \\
\cline { 2 - 7 }
\end{tabular}

1st Factor: Ability to use digital learning tools

I can comment, suggest and evaluate things online.

$3,15 \quad 0,70 \quad, 817$

I can join to the events on social networks.

3,18 0,715

I can use applications like Google Docs that are open for sharing.

3,21 $0,68 \quad 759$

I can work online for a purpose with cooperation.

I can create profiles on social media and manage them.

2,98 $0,80 \quad 709$

$2,75 \quad 0,99 \quad 663$

2nd Factor: Managing digital learning platforms I can do adjustments on digital platforms (visual or audio).

$\begin{array}{lll}2,61 & 0,91\end{array}$


I can upload files (visual or audio) to digital platforms.

$2,78 \quad 0,90 \quad, 781$

I can use several applications and contents for one purpose.

I can form digital objects (figures or digital designs).

I can use the version controls of the digital objects.

$2,74 \quad 0,85 \quad, 737$

$\begin{array}{lll}2,35 & 0,93 \quad 727\end{array}$

$2,41 \quad 0,98 \quad, 671$

I can publish the digital content (in platforms like

WEB, PDF, e-book, blog or video).

$2,54-0,98$

, 658

3rd Factor: Ability to use advanced level digital tools

I can use Google Adsense tool.

$2,07 \quad 0,94$

0,94

,783

I can make a web list on Google.

$2,08 \quad 0,95$

,715

I can organize advertising campaigns by using

several online platforms.

2,08 0,95

I can write a QR code and manage it.

I can create an application.

$\begin{array}{lll}1,63 & 0,81 & , 688\end{array}$

$1,78 \quad 0,87 \quad, 666$

$2,21 \quad 0,96 \quad, 656$

I can use Twitter hashtags.

$2,36 \quad 0,96$

,567

\section{4th Factor: Security and ethics}

I can stay online in a secure way.

2,65 0,93

770

$3,12 \quad 0,75$

,715

an ethical way in online platforms

$2,74 \quad 0,87$

,665

$2,84 \quad 0,83$

, 539

different target recipients.

Corevalue

Declared variance (\%)

11,306

51,392

0,897

2,154

9,790

1,349

0,850

Cronbach Alfa

$0,924 \quad 0,897$

3,865

Note: 1=Definitely do not agree, 4= Definitely agree

As seen in Table 6, these four factors together explain $70 \%$ of the total variance. The first factor is named as "ability to use digital learning tools". The 5 sub items of this factor are about the capabilities of using digital tools for basic learning purposes. The first factor, "ability to use digital learning tools" explains the biggest part of the total variance with $51 \%$.Using Google documents and social networks are the two items that have the highest means under this factor.

The second factor is named as "managing the digital learning platforms". The 6 sub items of this factor cover the attitudes of the learners' abilities to use digital platforms at basic level. "Managing the digital learning platforms" explains $10 \%$ of the total variance. Uploading files to digital platforms and using significant applications are the two sub items with the highest means.

Third factor is named as "ability to use advanced level digital tools". The 7 sub items of this factor include the statements about learners' abilities to use digital platforms at an expert level. This factor explains $6 \%$ of the total variance. The item with the highest mean within this factor is about learners' acting as a moderator for an online group. The low means of the items within the second and the third factors can be considered as an indicator showing how limited the learners' abilities to use digital technologies are. 
The last factor about using digital technologies is the aspect of "security and ethics". The 4 sub items of this factor cover the statements related with doing secure operations in digital platforms and also the right of ownership and ethical behaviors. This factor explains $4 \%$ of the total variance. Depending on the means of the answers about these items which learners have replied, it can be said that they do not know much about this issue.

When these factors are evaluated all together depending on the variance ratios, the first factor "managing the digital learning platforms" has more priority compared to other factors. It can be stated that the variance which is explained by these three factors within factor analysis has a $70 \%$ share, which can be considered pretty high.

\section{Conclusions and Recommendations}

When the digital literacy competence of open and distance learners is analyzed, it can be said that they have the basic competences of digital literacy. It has been pointed out that learners have the skills to use information and communication technologies at a basic level. They need training on how they can use the digital tools more efficiently for the purpose of learning. As McLoughlin (2011) stated, there is still training need for learning on digital literacy skills and digital competencies.

Results of the learning habits can be summarized as follows:

- Participants generally prefer learning through graphics or visuals, through listening, and through written materials. According to Fleming and Mills (1992), these choices are conceptualized as visual, auditory, and reading-writing learning styles.

- Majority of participants are dependent learners and they prefer face to face education. According to Grasha and Reichmann (1996), they enjoy authority figures for specific guidelines on what to do.

- Participants are usually not competitive learners. According to Grasha and Reichmann (1996), competitive learners enjoy competing with other students in a course for the rewards that are offered, rather than learning collaboratively within a group (Kay et al., 2009).

- Most of the participants consider having problem solving and project working skills to deal with educational difficulties. We can say that they have inquiry skills including the ability to investigate resources (Kay et al., 2009).

It is observed that the ratio of using personal computers is high but the use of new generation technologies like smart phones and tablets are not common among the learners. This situation may be due to the fact that the prices of the new generation devices are high. Together with this, it may also rise from the fact that necessity to use these devices in educational settings is not created. Anadolu University's mobile learning and interactive e-book services that have occurred within the context of e-learning transformation may cause a necessity and encourage the learners to use new generation information and communication technologies. Learners' adaptation to new generation technologies is important for them to form new learning habits like learning anywhere and anytime. Otherwise in the near future, facing disparity among the learners and this leading to a digital gap will be inevitable (Goodfellow, 2011). 
It is observed that the learners have the capability of- including skills like- solving problems, working in cooperation for projects, trusting themselves in communicating, reaching the information, analyzing it, evaluation and transmitting it. In terms of designs, they prefer visual learning platforms and by this way they have the ability to read, comment, and understand the information which is given with pictures and graphics. Their apparent dislike of collaborative online group work may be problematic as this is often a way in which modern businesses work. This may provide a unique opportunity to promote collaboration in education to support employability. Taking into account all of these, further research is needed to explore how to increase the use of digital tools efficiently for the purpose of learning and also how to design learning environments to improve distance learners' digital literacy.

\section{References}

Altunisik, R., Coskun, R., \& Bayraktaroglu, S. (2012). Sosyal bilimlerde araştirma yontemleri [Research methods in social sciences]. Sakarya: Sakarya Kitabevi.

Claxton, G., Powell, G. \& Chambers, M. (2004). Building 101 ways to learning power. Bristol, UK: TLO.

Covello, S. (2010). A review of digital literacy assessment instruments. Syracuse University School of Education/IDD \& E, IDE-712: Analysis for Human Performance Technology Decisions. Retrieved on 22 Jan 2013 from http://www.apescience.com/id/fulltext/ research-on-digital-literacy-assessment-instruments

Daniel, J. S. (1996) Mega-universities and knowledge media: Technology strategies for higher education. London: Kogan Page.

Fleming, N.D. \& Mills, C. (1992). VARK: A guide to learning styles. Retrieved on 10 July 2013 from http://www.vark- learn.com/english/page.asp?p=categories

FutureLab. (2010). Digital literacy across the curriculum handbook. Retrieved on 22 January 2013 from http://www.futurelab.org.uk/sites/default/files/Digital_Literacy_handbook _0.pdf

Gilster, P. (1997). Digital literacy. New York: John Wiley and Sons.

Goodfellow, R. (2011). Literacy, literacies, and the digital in higher education. Teaching in Higher Education, 16(1), 131-144.

Grasha, A.F. \& Riechmann, S.W. (1996). Student learning style scales. Retrieved on 19 July 2013 from http://academic.cuesta.edu/wholehealth/disted/about_styles.htm

Hadfield M., Jopling M., Royle K. \& Southern L. (2009). Evaluation of the Training and Development Agency for Schools' funding for ICT in ITT Projects. London: TDA.

Hair, J.F, Anderson, R.E, Tatham, R.L., \& Black, W.C. (1998). Multivariate data analysis (5 ${ }^{\text {th }}$ ed.). Upper Saddle River, NJ: Prentice Hall.

Hunt, L., Eagle, L., \& Kitchen, P.J. (2004). Balancing marketing education and information technology: Matching needs or needing a better match? Journal of Marketing Education, 26(1), 75-88.

Kay, D., McGonigle, B., Patterson, W., \& Tabbiner, B. (2009). Next generation user skills report. Sero Consulting. Retrieved on 6 May 2010 from http://www.digital2020.org.uk/skills/ strands/nextgen 
Kerrigan, J.P. (2012). Digital literacies in transition. University of Greenwich. Retrieved on 22 January 2013 from http://www2.gre.ac.uk/research/centres/ecentre/projects/dl-intransition.

Martin, A. (2008). Digital literacy and the digital society. In C. Lankshear and M. Knobel (Eds.), Digital literacies: Concepts, policies and practices (pp. 151-177). New York: Peter Lang Publishing.

McLoughlin, C. (2011). What ICT-related skills and capabilities should be considered central to the definition of digital literacy? In T. Bastiaens and M. Ebner (Eds.), Proceedings of World Conference on Educational Multimedia, Hypermedia and Telecommunications 2011 (pp. 471-475). Chesapeake, VA: AACE.

Ozata, Z. \& Ozdamar-Keskin, N. (2014). Students preferences and opinions on design of a mobile marketing education application. Turkish Online Journal of Distance Education, 15(1), 189-205.

Ozdamar-Keskin, N., Yamamoto, G.T., Traxler, J., Demiray, U., \& Royle, K. (2012, November). Multiplatform M-learning system for more qualified courses. Paper presented at the 5 th International Future Learning Conference on Innovation in Learning for the Future 2012: e-Learning. Istanbul, Turkey.

Rivoltella, P.C. (2008). From media education to digital literacy: A paradigm change? In P.C. Rivoltella (Ed.), Digital literacy: Tools and methodologies for information society (pp.217230). Hershey, PA: IGI Publishing.

Royle, K. \& Hadfield, M. (2012). from 'posh pen and pad' to participatory pedagogies: One story of a netbook implementation project with 108 pupils in two primary schools. International Journal of Mobile and Blended Learning, 4(1), 1-17.

Shariman, T.P.N.T., Razak, N.A., \& Noor, N.F.M. (2012). Digital literacy competence for academic needs: An analysis of Malaysian students in three universities. Social and Behavioral Sciences, 69, 1489-1496.

Sharkey, J. \& Brandt, D. S. (2008). Integrating technology literacy and information literacy. In P. C. Rivoltella (Ed.), Digital literacy: Tools and methodologies for information society (pp. 85-97). Hershey, PA: IGI Global.

Simsek, A. (2004). Ogrenme bicimi [Learning style]. In Y. Kuzgun and D. Deryakulu (Eds.), Egitimde bireysel farkliliklar (pp.97-138). Ankara: Nobel.

Simsek, E. \& Simsek, A. (2013). New literacies of digital citizenship. Contemporary Educational Technology, 4(2), 126-137.

Correspondence: Nilgun Ozdamar-Keskin, Assistant Professor, Department of Distance Education, Open Education Faculty, Anadolu University, Yunus Emre Campus, Eskisehir, Turkey 